\title{
Faculty Respond to COVID-19: Reflections-on-Action in Field Education
}

\author{
Anne Dempsey ${ }^{1}\left[\right.$ Nicholas Lanzieri $^{1} \cdot$ Virge Luce $^{1} \cdot$ Cora de Leon $^{1} \cdot$ Juhi Malhotra ${ }^{1} \cdot$ Aminda Heckman $^{1}$
}

Accepted: 4 January 2021 / Published online: 22 January 2021

(C) The Author(s), under exclusive licence to Springer Science+Business Media, LLC part of Springer Nature 2021

\begin{abstract}
The field placement process has become increasingly challenging for schools of social work, particularly for large graduate programs situated in urban centers with competing schools. The unprecedented circumstances created by the COVID-19 public health crisis further strained the placement process, revealing a delicate balance of interdependent systems that schools must address when confronted with an unforeseen disruption of field education. This paper reflectively examines the steps taken by the field faculty and department of one large school of social work to address the impact of the pandemic on field education and its placement process. Utilizing crisis and shared trauma perspectives, the field disruptions, continuity of learning, contingency plans, and the attendant anxiety caused by COVID-19 are discussed, as are the lessons learned. Though COVID-19 has significantly altered the placement process, this reflective frame allows faculty to take the lessons emerging from the crisis and use them to improve services and learning opportunities for students in the future.
\end{abstract}

Keywords COVID-19 $\cdot$ Anxiety $\cdot$ Shared trauma $\cdot$ Field education $\cdot$ Field placement $\cdot$ Pandemic response

\section{Introduction}

Our Field Learning and Community Partnerships (FLCP) team is accustomed to challenges in the field placement process, as we teach and administer the field curriculum area within a large graduate school of social work in a northeastern metropolitan city. Field placement at the School is a year-round endeavor to accommodate students enrolled in seven MSW degree pathways and a Bachelor's program starting field at various times throughout the academic year. Decades of experience in placing a diverse student body have taught us to understand the nuances of the process such as the fit between student and setting, student readiness to engage in field education, and student expectations meeting the reality of the professional world of social work. Those nuances are borne out by the field education literature (Asakura et al. 2018; Bogo 2015; Bogo et al. 2016; Wayne et al. 2010). Field educators across North America must find agency settings that meet a variety of requirements: the capacity to provide students with field instruction by a trained MSW field instructor, substantive and appropriate

Anne Dempsey

anne.dempsey@nyu.edu

1 Silver School of Social Work, New York University, New York, NY, USA field learning assignments consistent with the competencies set forth by the Council on Social Work Education Educational and Policy Accreditation Standards [CSWE EPAS] (CSWE EPAS 2015), and meeting the required number of hours dictated by CSWE and the School. An additional challenge is that the School has four campuses located in different states and counties in city, suburban, ex-urban, and global sites, historically serving approximately 1000 students. However, the circumstances created by the COVID19 public health crisis truly humbled our perceptions of the delicate balance of interdependent systems that our School had to address when confronted with the unforeseen consequences of a pandemic.

This reflective paper reviews how the FLCP addressed the challenges of field disruption, student replacement, and obtaining remote field opportunities during the Spring semester of 2020 at the epicenter of COVID-19. To ground this reflection, the authors utilized the concept of shared trauma to better understand the impact of the crisis on our practice as educators and administrators. Shared trauma is defined as an experience in which clinicians are exposed to the same collective trauma as their clients (Baum 2014; Dekel and Baum 2010; Tosone et al. 2003, 2012). This concept was extraordinarily helpful in examining our practice as educators and administrators during this world-wide health crisis, as we attended to the educational, emotional, 
and logistical needs of our students. Crisis is defined as a disruption that causes one's usual capacity for coping to be overwhelmed resulting in apparent distress and difficulties in functioning (Roberts and Otten 2005). The COVID-19 crisis engendered significant anxiety and disruption of the capacity to cope within the student body. As we know from the literature, anxiety and emotional regulation difficulties are challenges for social work students even under typical circumstances, as they are influenced by underlying mental health issues, confidence about performance and decisionmaking, previous experiences of trauma, and, importantly, the quality of the field instructor relationship (Baird 2016; Goodyear 2014; Knight 2019). In fact, Gelman and Baum (2010) found that American students reported significantly higher levels of anxiety in comparison with their Israeli counterparts. The COVID-19 experience and sudden disruption to field education caused an increase in stress during an already significant period of transformational change for students (Farber and Reitmeier 2019).

Field education leaders hold multiple roles within a school of social work such as the roles of educator, administrator and clinician (CSWE EPAS 2015; Holosko and Skinner 2015; Wertheimer and Sodhi 2014). In keeping with the concept of shared trauma, our varied roles were compromised by personal responses to the pandemic: fear of the unknown and the stress of managing a large curriculum area and logistical operation, all while attending to responsibilities as caregivers, personal medical issues, and the physiological impact of stress in an uncertain world. As administrators, despite the uncertainty, the FLCP had to decide on a course of action that would protect the health of our students by maintaining the School's and state's public health policies, while preserving relationships with agency partners. The COVID-19 crisis required social work educators to make these delicate decisions without significant information or previous relevant experience (Findley et al. 2017; Regehr 2018). As educators, we had to facilitate teaching and learning around crisis response, appropriate termination, and self-regulation as part of holistic competence in social work practice (Baird 2016; Bogo et al. 2014; Gelman 2004; Mirabito 2006; Roberts and Otten 2005). As trained clinicians, we were pained by the loss of service to clients and the meaning of that loss for students and agency partners; these feelings in particular caused doubt as to whether our administrative and educational decisions were sound.

The COVID-19 crisis stirred anxiety, as is common, particularly when there is lack of clarity about next steps and when decision makers feel out of control (Mirabito 2017; Regehr 2018). We observed significant anxiety at all levels of the school community, including within ourselves (the FLCP), the school's leadership, students, field advisors, and agency partners. However, as with most crises, there were also opportunities for growth and a sense of resilience, both individually and as a collective (Nuttman-Shwartz 2015; Straussner and Calnan 2014; Tosone et al. 2003; Tosone 2011; Walsh 2003). This reflection, focused on crisis, anxiety, and shared trauma, illuminates areas of potential change and development in our teaching practice as field educators, and in field education as a whole. Composite student vignettes represent the particular concerns and needs of international and accelerated students and our efforts and challenges in supporting them. To contend with the ambiguity of the continuing COVID-19 pandemic and to inform our plans for the future, we also delineate lessons learned from the initial management of field education during the pandemic, and reflect on the evolution of the field landscape as the pandemic continues.

\section{Shared Trauma, Crisis, and Anxiety in an Uncertain World}

In January 2020, the School experienced a preview of the implications of COVID-19 for field education when the students, faculty, and agency partners at our small global campus site were affected in unprecedented ways. As required by public health regulations, students' classroom and field experiences were disrupted and many community members self-quarantined. While administrators successfully problem-solved so that the students could meet educational standards and field competencies, the FLCP did not adequately plan for the COVID-19 crisis upending the field education program at our northeastern urban campus. We did not recognize that in a few short months our U.S. campuses would also be under the threat of this new virus, which would require FLCP leadership to be flexible and creative in the face of deep shifts in field education.

In mid-March 2020, the state and city governments initiated steps to safeguard public health in light of rising COVID-19 infections in the city. School administrators and the FLCP leadership were required to make concrete decisions about how to manage field education for approximately 1,000 students placed in over 600 agencies. The number of students and agency partners alone were enough to trigger fear and concern as we tried to understand the viable options in a rapidly shifting environment. The School based its decision to cease all in-person field activity on the information that was known at the time and also found guidance through section 6.01 of the NASW Code of Ethics (NASW 2017) regarding social workers' responsibility to the general welfare of the broader society. Accordingly, to ensure student safety, the safety of clients, and of the School's agency partners, the FLCP decided to suspend in-person field placement as of March 12, 2020. As the first of the schools in the metropolitan area to take such action, there was anxious uncertainty about this decision. Field education, 
particularly for clinical social work with individuals, families, and groups, has traditionally relied heavily on in-person relationship building and in-vivo experience of the agency setting and field instruction (Bogo 2015). The public health crisis necessitated physical distance and connection via technology, thereby depriving field education of its main methods of transmitting knowledge and skills-focused instruction. Our students, agency partners, and faculty needed clarity, decision-making, and planning as to the next steps in field education; yet, at times, this work felt insignificant in the midst of so much illness, loss, and community need.

\section{Cessation of Field Education: A Shared Trauma}

Students spend the majority of their educational hours engaged in field learning. They travel to every part of our major urban center collectively providing 650,000 hours of field service per year (Smith personal communication, May 12, 2020). By mid-March 2020, students had developed important relationships with individuals, groups, families, programs, and communities, as well as field instructors and colleagues. Communicating about the cessation of their inperson work was a delicate task and the significance of field learning in students' social work educational experience required timely, cogent, and accurate communication. A specific message was sent to each of the constituent groups: students, agency partners, and field advisors. In the School, field advisors teach an integrated Practice/Field course in the generalist practice year and serve as a liaison between the School, the agency, and the student to support learning. In addition to logistical information, the communication notified field advisors and students of contingency assignments to be completed by students during the interim period. These assignments were designed to continue enhancing students' critical thinking through the use of reflective exercises focused on the CSWE competencies and on anti-oppressive practice, social justice, standpoint theory, and critical race theory. Learning theory makes it clear that specificity, transparency and organization helps to mitigate the effects of ambiguity and can help students with concentration and synthesis (Dalsgaard 2009) so we attempted to be succinct and supportive for both students and advisors. Generally, constituents were receptive to the first round of communications and conveyed understanding of the circumstances. However, reactions to the subsequent communications were far more varied and are discussed below.

\section{Student Response}

The large and diverse student body expressed mixed emotions that included confusion, relief, understanding, disbelief, panic, disagreement, anger, sadness, anxiety and fears surrounding the impact on their social work education.
These feelings are similar to those identified by Tosone et al. (2003) reporting on the reactions of student clinicians as they worked with clients after the events of September 11, 2001. In the initial months of the pandemic, students voiced concerns to field advisors, instructors, and also through social media, ranging from disappointment to anger to fear, and from fear to frustration. At times, we had a sense that students blamed the FLCP for the disruption to their field experiences. It has been noted that student discontent is often aired in a public forum, such as social media, to provide both momentum and traction for a particular situation or social movement (Koshkin et al. 2017). The student discourse, including negative comments, seemed to exacerbate anxiety on all levels: for the students, field advisors, instructors, the School leadership, and the FLCP team. The anxiety, once reflected on and managed, also pushed the FLCP's reflective process and challenged leadership to consider how to do better in administration, pedagogy, and in planning for future disruptions.

Although the School attempted to make decisions rationally and to communicate those decisions clearly to students, its complex system of pathways to the MSW degree made it difficult to address questions in a straightforward manner. To communicate inconsistently during a crisis period is not an ideal practice in terms of supporting students through the uncertainty. Even with reassurances that students would earn full field credit for the spring semester, students continued to be overwhelmed by the information. Some interns found the forced (and sudden) termination process to be difficult (Gelman et al. 2007). Forced termination was especially difficult for students whose agencies could not support a remote termination process with clients through phone or videoconference. Some students inquired about staying on at their agency, despite the school-wide directive to work remotely or complete the contingency assignment, because they felt they were the only person who could help their client, revealing a lack of experience in professional termination with clients (Gelman 2009). Students in their first field placement experiences had not studied techniques or prepared for the emotional impact of termination on clients and themselves.

During field advisement meetings, held via videoconference, some students continuing remote work expressed feeling conflicted. Although they appreciated the positive impact their work had on clients, they felt burdened by caregiving responsibilities, and revealed concerns about limited resources, including private space to conduct sessions and technology to facilitate communication. Others felt uncomfortable continuing their clinical placements at home without live field instruction, which many agency partners were unable to provide during the height of the initial crisis. Nuttman-Schwartz and Dekel (2008), in reporting on a training program for students to prepare for shared trauma situations, 
identify that new professionals are most at risk to the challenges of working within a shared traumatic reality. In our experience, students whose first field placement experiences were cut short by COVID-19 were the most upset and confused about how to continue to both learn and serve clients.

\section{Field Advisor Response}

Field advisors, whose roles expanded and intensified during the crisis, were also anxious, frustrated, and, at times, angry. After the dissemination of the FLCP's communications, field advisors' queries revolved around the following subjects: (1) how to manage students who had field disruptions prior to COVID-19, (2) what should be taught in the field portion of the integrated Practice/Field Learning course, (3) how to keep track of students doing remote work, (4) what assignments constituted acceptable remote work, and (5) what would happen to continuing summer semester students who had no remote field assignments. As was previously noted, field advisors had not discussed certain subject matters like termination in the integrated course and now found themselves scrambling to introduce the material earlier than expected. Students asked field advisors for answers they did not yet have from field leadership because the relevant information (issues of safety, public health requirements, the larger university's decisions, and policies from accrediting bodies, and the future of the field placement options) was unclear. Students became increasingly anxious sitting with uncertainty and this impacted the advisors' capacity to manage the group's feelings in the classroom. Clearly, the field advisors' work in trying to navigate the dynamics between field agency, School and student, normally a laborious and resource intensive endeavor (Wayne et al. 2010), was made even more so by the pandemic. To provide them with more support, the field faculty offered three drop-in sessions via teleconference for advisors and also visited individual classes (virtually) to answer questions for students.

\section{Agency Partner Response}

Social work students are a valuable resource to agencies (Fortune et al. 2001) and the knowledge agencies impart, particularly through field instruction, is indispensable for student development. When the pandemic disrupted field learning, many field instructors were determined to keep students connected with clients, through telehealth, videoconference, and phone. However, remote social work practice and telehealth had not been previously attended to within the curriculum, as telehealth was often discouraged or forbidden in agency practice. There was little in the social work education literature at the time that focused on guiding students in telehealth practice and indeed the field had reservations about the uptake of technology in social work practice (Wolf and Goldkind 2016). However, it was clear that telehealth would play a role in all direct practice and clinical social work settings during the pandemic. The FLCP collaborated with an agency partner that specializes in training social workers so that students and field advisors could access telehealth training resources online.

Field instructors are indeed essential partners in teaching. They worked to bring our students up to speed quickly, as they themselves developed skills and protocols for remote social work practice. Many students adeptly accommodated the changes and tried their best to maintain communication with their respective agencies. Research has consistently shown that a supportive field instructor relationship is crucial to student learning (Fortune et al. 2001; Goodyear 2014). Indeed, student satisfaction has been directly linked to their perception of the quality of supervision being provided (Raskin et al. 2008). The abrupt termination due to COVID-19 affected each agency differently, depending on their internal resources. Many agencies were able to accommodate the sudden ending by taking responsibility for client services and supporting a termination process; some were relieved to end early so they could divert resources from supporting students to their own direct work with clients. A few of the School's agency partners, specifically those hosting second year students, were displeased that the School was ending field a month early. As an example of the shared trauma and parallel process dynamic, the removal of students from in-person field resulted in additional hardship for some agency partners, who were struggling to respond to the crisis as well. A community-based mental health agency that has partnered with the School for 15 years wrote an email the very next day decrying the decision, noting how detrimental our actions were to clients and student learning, while also questioning our ethics.

Certainly, it was understandable that agency partners wanted to retain the student interns since they were already trained to do the work, and as noted, many students wanted to continue the work. With any crisis, there is a reaction to the destabilizing event and resistance to its effects (Mirabito 2017; Regehr 2018). In responding to the agency's concerns, FLCP took a teaching perspective and rooted its rationale for ceasing in-person field to learning objectives and the educational nature of the student's presence in the agency. Social work interns function as learners and are required to be buffered from situations and environments to which professional social workers are exposed (Homonoff 2008). While the pandemic certainly made boundaries more porous and standards more relaxed, the School needed to provide our students with as much guidance and protection as possible in a remote learning environment. To further hone its educational approach, FLCP needed to ensure that all students were exposed to similar field learning objectives and experiences. Equity is important in field education, as are 
matters of inclusive teaching, which makes every attempt to provide diverse students similar access to learning opportunities (Hitch et al. 2015; Reupert et al. 2010). Consequently, as field educators, the FLCP was concerned with the needs of students who were discharged abruptly and those who were not receiving field instruction because of the overwhelming nature of the early crisis. Early termination created a more equitable and balanced experience for students.

\section{“Normal" Field Disruptions: Magnified by Crisis}

Prior to COVID-19, field disruptions were not unheard of in schools of social work. A number of students each year experience field disruptions in completing their internships, thereby jeopardizing expectations for fulfilling the Masters of Social Work curriculum. Each year, approximately $10 \%$ of students in our School experience a field disruption. Disruptions are rooted in various sources including, students or agency parameters not meeting expectations, disillusionment with the work, issues with field instruction, and agency cutbacks and changes (Holtzman and Raskin, 1989; Parker 2010). Disruptions have the potential to significantly impact all parties: students, the field agency and the school (Parker 2010). Students find disruptions in placement as having negative implications to the continuity of their education, and as compromising their financial investment, sense of self-efficacy, and general wellness (Holtzman and Raskin 1989; Parker 2010). Students are also concerned that a disruption in field education will compromise their future career prospects.

Virtually every student in our school experienced a disruption in field education during the initial COVID-19 crisis. While the FLCP tried to promote the idea of life-long learning in social work and that increased flexibility and telehealth skills would be benefits of this crisis experience, we failed, at times, to fully acknowledge the loss and frustration that students were feeling. In the overwhelming experience of a shared trauma, the professional can find themselves experiencing lapses of empathy, which may result from what Baum describes as the "trap of conflicting needs" (2012, p. 37)-the need to distance ourselves from the shared trauma and the need to derive self-esteem from our view of ourselves as competent helping professionals and educators. FLCP wanted to solve the problem while students were still grappling with the unexpected nature of the disruption. Pressure from our role as administrators hampered the FLCP's ability to perform as educators and helping professionals. All levels of the system (students, faculty, school leadership, and agency partners) were unsettled by the uncertainty from the university and public health and city officials.
Under ordinary circumstances, finding new field placements for disrupted students is challenging. Not every agency is a good fit or match for the student, and consideration must be given to field type, experience, level of appropriateness, and expectations (Holtzman and Raskin 1989). Even when such matters are identified by all parties there are other challenges to finding a suitable field match. Buck et al. (2016) have noted facets of the social and educational spheres that are contributing to some of the difficulties: "(1) imbalance between supply and demand of adequate field sites; (2) diverse and complex student needs; (3) recruiting and maintaining high-quality field sites and field instructors (supervise social work interns); and (4) economic trends and pressures" (p. 404, citing the North American Network of Field Educators and Directors 2015). Ayala et al. (2018) have also written about a crisis in field education citing saturation in the field placement landscape and lack of time and capacity to teach in the field setting. As was previously noted, the pandemic further restricted the field landscape, causing tension and disappointment for students and causing field educators to explore innovative and non-traditional solutions to this crisis.

While the FLCP was able to replace students continuing from the spring semester into summer (approximately 130 students), the nuances of the situation were challenging. Many of these first year MSW students had only just begun their first experience in field work, and so the inexperience with agency practice became an impediment to summer agencies accepting these students for remote work. Generalist practice students were in the process of being interviewed for their specialized practice field placement for Fall 2020 and their lack of experience complicated their ability to successfully interview for a specialized practice field placement. For example, several potential agencies expressed reluctance to interview generalist practice students who had minimal training due to the pandemic disruption. Finally, the harsh reality of COVID-19 was settling in as some of our students reported family members being seriously ill, or were ill themselves, and consequently they were unable to participate in interviews. The field faculty were caught between the expectations of our students and the pandemic reality which exacerbated an already overtaxed field landscape, leading to feelings of helplessness, fatigue, and concern in the face of disappointed students.

\section{Student Vignettes}

In the end, the student is the central focus for faculty in field education and our efforts were primarily geared toward shoring up their disrupted field placement experiences and adhering to our educational standards. To illustrate the challenging nature of the replacement process for continuing 
students in the midst of COVID-19, two student vignettes are presented below, one centered on working with an international student between the Spring and Summer semesters and the other focused on an accelerated student in the generalist practice year. The vignettes are composites of student situations encountered in field education during COVID-19.

International students presented with unique barriers to field learning during the initial COVID-19 crisis. The literature indicates that international students experience cultural isolation, a clash in values, and can be emotionally vulnerable when participating in placements outside of their home country (Fox 2017). This "culture clash" also contributes to a sense of being "othered" (Fox 2017, p.11), which the pandemic further exacerbated. Although most international students remained in the U.S., a few returned to their home country before travel restrictions were implemented.

\section{International Student}

Sara, a 28-year old international student from China, was enrolled in the full-time MSW program. Sara was asked to leave her agency setting in an elementary school just prior to the pandemic. The field instructor assessed her as having difficulty with self-reflection and examining her social location/positionality to understand its impact on her work with clients. Sara's perspective was that the field instructor was highly critical. Typically, after a student is terminated from an agency, students are expected to participate in critical reflective exercises before moving forward with another placement match. The faculty required a reflection writing exercise but Sara's contribution indicated minimal accountability. Therefore, it was more challenging to find a viable new setting for her learning. Sara interviewed but was declined by two agencies. The faculty advisor was not accessible to support the student in this process due to the stresses of transitioning to emergency remote teaching and advising. A persistent collaborative effort between the field coordinator, agency partners, and academic advisors resulted in a remote placement at an adult shelter setting to be conducted from the student's home country. Concrete challenges such as negotiating a secure internet connection and privacy concerns were discussed with the student; modest financial support for the internet connection was offered by the School. Sara's new field instructor was recruited specifically to help her with her reflective practice skills. Sara initially planned to return to the U.S. prior to completing her specialized practice year (a tentative plan due to potential visa or travel restrictions), but then was diagnosed with COVID-19 (she later recovered well). Sara ultimately decided to take a leave of absence to ensure that she could complete her next field placement in-person.

It is clear that international students were among the students most impacted by the initial disruption, and those who remained in the U.S. felt isolated, fearful, and unsupported being far from familiar environments and support networks while managing the experience of COVID-19. For international students who returned home, there were complex barriers to the continuation of field education. One of those stressors was the complication of living in one time zone while working within another time zone. Identifying agencies with the capacity for web-based platforms, finding qualified field instruction for students who needed significant structure and guidance in remote practice, and locating an agency that would help the student meet the required competencies were significant. Students had to secure funds for unplanned international travel, were uncertain about visa approval upon returning to the U.S., and concerned that a second wave of the pandemic would ultimately disrupt field learning again. Farber and Penney (2020) highlight the importance of the relational context for social work students with teachers and advisors, a context from which Sara was separated by having left for her home country quickly before travel restrictions were instituted. Without this close, relational context, Sara's replacement process was challenging. Her underdeveloped professional identity and limited experience with reflective practice could not be attended to with the same diligence that could have been offered in person and outside of a crisis context. Other international students who presented with more favorable professional readiness experienced a more expedient process for overseas placement.

Affinity group leaders for the international students mobilized to advocate for remote field placements as well as the quality of their learning. Multiple meetings were held by field faculty to address these worries and to provide brave spaces for them to express their lived experiences. At times, the faculty were impatient and perhaps desensitized to the concerns of the international students, as we were preoccupied with our own experiences of the pandemic. Fox (2013) reminds us of the concept of "starting where the student is at," which perhaps is where the focus should have been. Students' increased isolation due to the public health situation, coupled with the dissonance they experienced between their own cultural identities in comparison to their host nation, exponentially increased their stress level. The faculty were focused on the pedagogical approach to field education despite the pandemic, while the students were focused on survival and emotional upheaval in a heightened crisis while living far from their support systems in a new country. Engaging with the international student community at the School is a work-in-progress and the faculty must continue to examine its approach in meeting this goal. An important approach will be to help students recognize their own reservoirs of resilience. Promoting resilience and community building will help students demonstrate greater reflective ability (Fox 2017). 
Continuing generalist practice students in the accelerated program also presented specific issues and needs for the replacement process during the COVID-19 crisis.

\section{Accelerated MSW Program Student}

Stacy was a generalist practice student, a career changer who chose the accelerated track, and was placed at an early childhood setting during the Spring 2020 semester. Stacy is described as a strong student, eager to learn, with high expectations of herself and her learning experience, as is common with career changers. Due to extensive agency clearance and onboarding procedures for work with children, Stacy did not start working directly with clients until the end of February. After only two weeks in the placement, Stacy was removed from her in-person internship and was told she would be reassigned to an agency that would allow her to conduct sessions virtually. Understandably, Stacy was angry and upset. She felt the delay in starting her original internship was the agency and the School's fault and she felt ill-equipped to engage patients virtually. Stacy felt she barely had time to learn how to engage in person. She was concerned about privacy and confidentiality as she was living with several family members in a small space, with unreliable internet service. Stacy expressed frustrations to her field advisor/practice professor. A group conversation took place between the student, the student's academic advisor, and the field placement coordinator. While Stacy was still unhappy with the situation, the coordinated effort among all faculty assisted Stacy in feeling that she was not alone and her concerns were being heard, a successful intervention given the shared trauma experience for all parties. Stacy was ultimately replaced in a remote opportunity at a supportive housing setting, and was placed for her next field internship working with clients in a psychiatric setting.

This student vignette demonstrates a dilemma that FLCP experiences regularly and was intensified during COVID-19: events outside the control of faculty and coordinators often impact a student's educational experience in field placement and students feel resentful of this fact. Field coordinators walk a fine line between maintaining relationships with agency partners and advocating on behalf of students, and students often come to the process expecting that the school can influence all aspects of an agency setting. In Stacy's case, she was frustrated with losing the early childhood experience, which was primarily a side effect of the COVID-19 crisis. Moving students toward a stance of flexibility and openness to unexpected situations is challenging in the best of times; during COVID-19, the anxiety caused greater levels of frustration and sadness about what students perceived as lost opportunities. Stacy's various supports at the school (practice professor/field advisor and academic advisor) worked diligently to help her acknowledge the loss of her perceived perfect placement and the frustrations about the delay. FLCP helped students adapt to the circumstances while also guiding them in identifying the learning available within the loss. Transparent communication, validation of her feelings, and support from the academic advisor and field coordinator played a crucial role in keeping Stacy engaged in her learning process. It is possible that Stacy would have benefited from a formalized contingency plan for students out of field placement, while undergoing the replacement process, as is described in the Lessons Learned section below. A robust contingency plan (which we did not have in place at the time) would have provided continued learning and a holding environment for any disrupted student, as is recommended by Farber and Penney (2020).

\section{Lessons Learned}

Dekel and Baum (2010) found that there are both negative and positive consequences for mental health professionals who work within a "shared traumatic reality" (p. 1929). Our experience is similar, including emotional distress and a negative impact on professional competence, as well as personal and professional growth and new perspectives on the work. Social workers attempt to bring order and clarity to chaotic situations and manage ambiguity while staying regulated especially when faced with the unknown. Through this process of "reflection-on-action" (Schön 1983), the FLCP recognized its missteps and remained open to understanding the learning opportunities: deepening our creativity and flexibility, being more inclusive in decision-making processes, and increasing its skills in supporting students, while holding fast to educational standards. Reflections on the student vignettes and our overall experience helped us delineate lessons for future educational practice.

\section{Reflections on Our Role as Educators}

The initial COVID-19 crisis caused us to re-evaluate our role as educators. It is important to distinguish between our roles as administrator and educator, and to be more explicit about these dual roles with students, so as not to use teaching as a means to push administrative solutions, as we may have done when suggesting too soon that international students see the learning within the crisis. Field faculty can assist social work students disrupted by COVID-19 or any other factor in an intentionally compassionate, patient, and process-oriented manner. As previously discussed, a crisis can evoke or retrigger a vulnerable state in people, but rationally directed support and guidance can help mitigate a recovery phase (Mirabito 2017). The FLCP has learned that providing clear and consistent communication to students in a timely manner was key in creating some measure of calm, 
from both an administrative and educational perspective. In order to ensure that future communications (both written and verbal) are responsive to student's needs, it will be important to increase our capacity for a relational approach to field coordination (Asakura et al. 2018). The stress of the pandemic and the administrative demands, at times, reduced our capacity to be compassionate and curious about the student experience. Additionally, student representation on our committees and within the work of the department may be helpful in fostering more collaboration in future emergent situations.

In the height of the pandemic, it was difficult, at times, to find empathy for students living in safe environments who were demanding answers about their field placement assignment for the following year, while following accounts of increasing infections and overwhelmed hospital systems and providers. As Tosone et al. (2012) remind us, peer support and supervision are essential in shared trauma situations and this proved useful to the FLCP during COVID-19. Although we were not exposed to warfare during the pandemic, as was studied by Baum (2014), the authors' findings regarding five features of shared trauma work are similar to the pandemic experience: intrusive anxiety, immersion in professional role, role expansion, and changes in time and place of the work (isolated at home). Lapses of empathy (Baum 2014) have been demonstrated within the student vignettes. Working relationally and with attention to student identity is an ideal educational practice in field coordination and begins the process of training new students in the practice of clinical social work (Asakura et al. 2018). A primary dilemma in field education was laid bare by the COVID-19 crisis: large volume programs struggle to meet the pedagogical recommendations of Wayne et al. (2010) and the complex needs of students without adequate staffing and resources (Ayala et al. 2018; CSWE State of Field Education Survey 2015). To be able to access such support and provide relationally-focused field coordination from a teaching perspective, the School will need to consider increasing staff or faculty resources, thereby decreasing the volume of students we each individually serve.

\section{Reflections on Pedagogy in Field Education}

As Farber and Reitmeier (2019) tell us, the complexities of field education require faculty within schools of social work to take charge of the pedagogy in field, and the COVID-19 crisis has highlighted this responsibility. The loss of such an important curriculum area during the initial COVID-19 crisis and in subsequent months reinforced the centrality of the field experience for MSW students. To address this educational challenge, the faculty have since created a contingency Field Seminar for any student out of placement. The seminar builds on the learning objectives achieved in the Practice and Field Instruction courses through virtual simulations, role plays, videos, modules, webinars, and readings to showcase field-related learning. Skills are taught in the areas of therapeutic communication, engagement, assessment, goal setting, mandated reporting, motivational interviewing, family therapy, crisis intervention, mental health practice, and organizational evaluations. Field agencies are highlighted throughout the seminar to expand student's knowledge of the agency landscape in that area of practice. The weekly seminar meeting is led by an experienced agency practitioner who uses reflective exercises, role plays, and discussion to encourage critical thinking about practice in a group supervision format. An anti-oppressive and critical race theory lens is infused throughout the seminar. It became clear through the experience of COVID-19 that students were underprepared for the reflective process required of social workers in the midst of a crisis. Additional attention to preparing students for the reflective process in field education prior to entry may also grow from this endeavor.

\section{Reflections on Administration}

According to Kumar and Bahar (2019), equity refers to providing equal opportunities for success to a diverse group with different capacities, and this was a significant focus from an administrative perspective during the initial crisis. The School has been working toward an increased focus on diversity, equity, and inclusion. As in the international student vignette, student participation, in partnership with FLCP, resulted in successful replacement even in a crisis situation. Students aren't typically aware of the myriad factors that go into field placement decisions. Often, students bring their own priorities and wishes to the process, and during this time of COVID-19, they also contended with personal anxieties regarding the virus and their interrupted MSW education. Including students in the decision-making process ensures that students' expectations are not missed and that isolation and feelings of being "othered" for subgroups of students are not heightened.

The complexity of the administrative system for field education was illuminated by COVID-19. Since the initial crisis, the FLCP has created new systems to maintain data regarding remote, hybrid, in-person field placements, and rescinded placements. It has created off-site field instruction opportunities and hired additional staff. The FLCP is also handling the administration of an ever-changing Field Seminar enrollment by training new School-based field instructors to support students out of placement. Given the complexity, time, and effort of this monumental task, the commitment and support of the larger faculty in recognizing field learning as the signature pedagogy is essential (Wayne et al. 2010). 


\section{Reflections on School Leadership}

The initial experience of the COVID-19 crisis within our school confirmed field learning's place in the curriculum and has highlighted, for the School's leadership, the important role it plays for students, community partners, and the School's identity and functioning. A strong field education program is essential to attracting social work students and demonstrative of our educational commitment to develop students' skills and reflective capacities for advanced practice in clinical social work. Barriers to creating and maintaining a robust field education program are well-known to field faculty; they include placement shortages and saturation, recruitment and training challenges for field instructors to keep them apprised of curriculum changes and new academic content, the impact of chance on the quality of a student's learning experience, and the student as consumer rather than learner, with limited readiness for entry into field education (Ayala et al. 2018; Farber and Reitmeier 2019; Gushwa and Harriman 2019; Hay et al. 2019). As a result of COVID-19, these challenges are now better understood by the leadership of the school, as exemplified by their support of the contingency plan described above. The dual roles of faculty in field learning - both administrator and educator are also better understood-and resources have been put toward improving pedagogy and support for field advisors and field instructors.

\section{Implications for Field Education and Clinical Social Work}

It is now clear that this difficult, continuing crisis will provide opportunity for positive innovation, pushing the field education curriculum area to creatively meet students' educational needs. Rich, new field placements have been developed through proactive outreach. Meso and macro assignments, well-suited to remote work, have been made available. For example, a valued field instructor, provided individual and group supervision to five students within a mental health setting focused on meso and macro assignments. International and out-of-state students have been able to complete field education remotely, offering flexibility and support due to their unusual circumstances. Doctoral students and faculty have been engaged as on-site and off-site field instructors to enable placements where supervision was previously unavailable. Innovations like the Field Seminar will continue to support students who are disrupted from field placement to sustain their knowledge acquisition and to avoid delaying graduation dates. This will benefit students far beyond the end of the COVID-19 pandemic. Schools of social work should consider the use of simulation to prepare students for field education and to enhance the teaching of clinical social work practice when field education settings are not available as they once were (Kourgiantakis et al. 2019b). Simulation provides opportunities to practice the reflective process, for clinical practice skill development, and for students to be observed and receive feedback (Kourgiantakis et al. 2019a).

Agency partners are providing fully remote clinical social work field placements to students who attend school part-time while working full-time, a significant need for the contemporary social work student. Students are attending case conferences, trainings, and group supervision that would otherwise have been impossible before remote access became the norm, supporting the development of clinical social work skills. A significant number of local students were placed in clinical social work settings throughout the city and the surrounding area, which would ordinarily have been impossible due to location and travel time. For example, a local student was placed in a three-semester palliative and end of life care placement remotely in a nearby city and several students were placed in outpatient mental health with children and adolescents and adults throughout the surrounding area. Telehealth is a positive new development for clinical social work, increasing access and capacity to services for clients and training for students and professionals. Wilkerson et al. (2020) found that a significant percentage of users of their telehealth training program (offered during the pandemic) were engaged in clinical social work settings such as mental and behavioral health, child and family social work, private practice, and school social work. Certainly, training for providing effective and culturally sensitive telehealth services should be part of practice curricula moving forward.

\section{Conclusion}

As the pandemic has ebbed and flowed throughout the year, the FLCP team was personally impacted through loss of family members and friends, COVID infection, remote learning for our families, and managing the isolation and disruption to our lives so common in these unusual times. The student body continues to be overwhelmed by health issues, finances, family responsibilities, and pandemicrelated stressors that weigh heavily on their educational process. Agency partners continue to struggle with responding to clients and maintaining quality services during the pandemic, as well as in supporting students in a remote social work practice environment. COVID-19 revealed a "parallel process" of both anxiety and resilience among students, field advisors, field instructors, and agency partners (Kahn 1979). In this shared trauma context, efforts to provide meaningful and rich field education to our students continue to be challenging. The practice of self-care remains important in 
the face of the extraordinary workload for current-day field educators. This reflection, an examination of anxiety and the concept of shared trauma in field education during COVID19 , has engendered a deeper level of awareness of systems, practices, policies, pedagogy, and emotional responses. It serves the goals of achieving greater equity and inclusion and becoming more nimble in responding to field disruptions and crisis. The lessons that have emerged from this internal reflection provide a path forward for the signature pedagogy of the profession to utilize reflection in our pedagogy, even as the crisis of COVID-19 changes and abates.

\section{References}

Asakura, K., Todd, S., Eagle, B., \& Morris, B. (2018). Strengthening the signature pedagogy of social work: Conceptualizing field coordination as a negotiated social work pedagogy. Journal of Teaching in Social Work, 38(2), 151-165. https://doi.org/10.1080/08841 233.2018.1436635.

Ayala, J., Drolet, J., Fulton, A., \& Hewson, J. (2018). Field education in crisis: Experiences of field education coordinators in Canada. Social Work Education, 37(3), 281-293. https://doi. org/10.1080/02615479.2017.1397109.

Baird, S. L. (2016). Conceptualizing anxiety among social work students: Implications for social work education. Social Work Education, 35(6), 719-732. https://doi.org/10.1080/02615 479.2016.1184639.

Baum, N. (2012). Trap of conflicting needs: Helping professionals in the wake of a shared traumatic reality. Clinical Social Work Journal, 40(1), 37-45. https://doi.org/10.1007/s10615-011-0347-0.

Baum, N. (2014). Professionals' double exposure in the shared traumatic reality of wartime: Contributions to professional growth and stress. British Journal of Social Work, 44(8), 2113-2134. https:// doi.org/10.1093/bjsw/bct085.

Bogo, M. (2015). Field education for clinical social work practice: Best practices and contemporary challenges. Clinical Social Work Journal, 43(3), 317-324. https://doi.org/10.1007/s1061 5-015-0526-5.

Bogo, M., Katz, E., Rawlings, M., \& Logie, C. (2014). Using simulation in assessment and teaching. Alexandria, VA: Council on Social Work Education.

Bogo, M., Lee, B., McKee, E., Baird, S. L., \& Ramjattan, R. (2016). Field instructors' perceptions of foundation year students' readiness to engage in field education. Social Work Education, 35(2), 204-214. https://doi.org/10.1080/02615479.2015.1123689.

Buck, P. W., Fletcher, P., \& Bradley, J. (2016). Decision-making in social work field education: a "good enough" framework. Social Work Education, 35(4), 402-413. https://doi.org/10.1080/02615 479.2015.110907.

Council on Social Work Education. (2015). Educational policy and accreditation standards [Brochure]. Washington, DC: Council on Social Work Education.

Dalsgaard, C., \& Paulsen, M. (2009). Transparency in cooperative online education. International Review of Research in Open and Distributed Learning, 10(3), 1-22. https://doi.org/10.19173/irrod l.v10i3.671.

Dekel, R., \& Baum, N. (2010). Intervention in a shared traumatic reality: A new challenge for social workers. The British Journal of Social Work, 40(6), 1927-1944.

Farber, N., \& Penney, P. (2020). Essential and neglected: Transforming classroom learning through relationship. Journal of Teaching in Social Work, 40(2), 95-113. https://doi.org/10.1080/08841 233.2020.1726553.

Farber, N., \& Reitmeier, M. C. (2019). (Re) capturing the wisdom of our tradition: The importance of Reynolds and Towle in contemporary social work education. Clinical Social Work Journal, 47(1), 5-16. https://doi.org/10.1007/s10615-018-0666-5.

Findley, P. A., Pottick, K. J., \& Giordano, S. (2017). Education graduate social work students in disaster response: A real-time case study. Clinical Social Work Journal, 45, 159-167. https://doi. org/10.1007/s10615-015-0533-6.

Fortune, A. E., McCarthy, M., \& Abramson, J. S. (2001). Student learning processes in field education: Relationship of learning activities to quality of field instruction, satisfaction, and performance among MSW students. Journal of Social Work Education, 37, 111-124.

Fox, M. (2017). Student isolation: The experience of distance on an international field placement. Social Work Education, 36(5), 508520. https://doi.org/10.1080/02615479.2016.1215418.

Fox, R. (2013). The call to teach: Philosophy, process, and pragmatics of social work education. Alexandria, VA: Council on Social Work Education.

Gelman, C. R. (2004). Anxiety experienced by foundation-year MSW students entering field placement: Implications for admissions, curriculum, and field education. Journal of Social Work Education, 40(1), 39-54. https://doi.org/10.1080/10437797.2004.10778 478.

Gelman, C. R. (2009). MSW students' experience with termination: Implications and suggestions for classroom and field instruction. Journal of Teaching in Social Work, 29(2), 169-187. https://doi. org/10.1080/08841230802238328.

Gelman, C. R., \& Baum, N. (2010). Social work students' pre-placement anxiety: An international comparison. Social Work Education, 29(4), 427-440. https://doi.org/10.1080/026154709030090 07.

Gelman, C. R., Fernandez, P., Hausman, N., Miller, S., \& Weiner, M. (2007). Challenging endings: First year MSW interns' experiences with forced termination and discussion points for supervisory guidance. Clinical Social Work Journal, 35(2), 79-90. https:// doi.org/10.1007/s10615-007-0076-6.

Goodyear, R. K. (2014). Supervision as pedagogy: Attending to its essential instructional and learning processes. Clinical Supervisor, 33(1), 82-99. https://doi.org/10.1080/07325223.2014.918914.

Gushwa, M., \& Harriman, K. (2019). Paddling against the tide: Contemporary challenges in field education. Clinical Social Work Journal, 47(1), 777-780.

Hay, K., Maidment, J., Ballantyne, N., Beddoe, L., \& Walker, S. (2019). Feeling lucky: The serendipitous nature of field education. Clinical Social Work Journal, 47(1), 23-31. https://doi. org/10.1007/s10615-018-0688-z.

Hitch, D., Macfarlane, S., \& Nihill, C. (2015). Inclusive pedagogy in Australian universities: A review of current policies and professional development activities. International Journal of the First Year in Higher Education, 6(1), 135.

Holosko, M., \& Skinner, J. (2015). A call for field coordination leadership to implement the signature pedagogy. Journal of Human Behavior in the Social Environment, 24(3), 275-283. https://doi. org/10.1080/10911359.2015.1005519.

Holtzman, R. F., \& Raskin, M. S. (1989). Why field placements fail. The Clinical Supervisor, 6(3-4), 123-136. https://doi.org/10.1300/ J001v06n03_10.

Homonoff, E. (2008). The heart of social work: Best practitioners rise to challenges in field instruction. Clinical Supervisor, 27(2), 135-169. https://doi.org/10.1080/07325220802490828.

Kahn, E. M. (1979). The parallel process in social work treatment and supervision. Social Casework, 60(9), 520-528. https://doi. org/10.1177/104438947906000902. 
Knight, C. (2019). Trauma informed practice and care: Implications for field instruction. Clinical Social Work Journal, 47(1), 79-89. https://doi.org/10.1007/s10615-018-0661-x.

Koshkin, A., Rassolov, I., \& Novikov, A. (2017). Monitoring social media: Students satisfaction with university administration activities. Education \& Information Technologies, 22(5), 2499.

Kourgiantakis, T., Sewell, K. M., \& Bogo, M. (2019a). The importance of feedback in preparing social work students for field education. Clinical Social Work Journal, 47(1), 124-133. https://doi. org/10.1007/s 10615-018-0671-8.

Kourgiantakis, T., Sewell, K. M., Hu, R., Logan, J., \& Bogo, M. (2019b). Simulation in social work education: A scoping review. Research on Social Work Practice, 30(4), 433-445. https://doi. org/10.1177/1049731519885015.

Kumar, M., \& Bahar, O. S. (2019). Introduction to the issue on equity, collaboration, and empowerment in mental health research partnerships. Global Social Welfare, 6(3), 141-144. https://doi. org/10.1007/s40609-019-00159-y.

Mirabito, D. M. (2006). Revisiting unplanned termination: Clinicians' perceptions of termination from adolescent mental health treatment. Families in Society, 2, 171.

Mirabito, D. M. (2017). Social work theory and practice for crisis, disaster, and trauma. In F. Turner (Ed.), Social work treatment, interlocking theoretical approaches (6th ed., pp. 195-213). New York, NY: Oxford University Press.

National Association of Social Workers. (2017). NASW code of ethics. Retrieved June 10, 2020, from https://www.socialworkers.org/ About/Ethics/Code-of-Ethics/Code-of-Ethics-English.

Nuttman-Schwartz, O., \& Dekel, R. (2008). Training students for a shared traumatic reality. Social Work, 53(3), 279-281.

Nuttman-Shwartz, O. (2015). Shared resilience in a traumatic reality: A new concept for trauma workers exposed personally and professionally to collective disaster. Trauma, Violence, \& Abuse, 16(4), 466-475. https://doi.org/10.1177/1524838014557287.

Parker, J. (2010). When things go wrong! Placement disruption and termination: Power and student perspectives. British Journal of Social Work, 40, 983-999. https://doi.org/10.1093/bsjw/bcnl49.

Raskin, M. S., Wayne, J., \& Bogo, M. (2008). Revisiting field education standards. Journal of Social Work Education, 44(2), 173-188. https://doi.org/10.5175/JSWE.2008.200600142.

Regehr, C. (2018). Stress, trauma, and decision-making for social workers. New York, NY: Columbia University Press.

Reupert, A., Hemmings, B., \& Connors, J. (2010). Do we practice what we preach? The teaching practices of inclusive educators in tertiary settings. International Journal of Teaching \& Learning in Higher Education, 22(2), 120-132.

Roberts, A. R., \& Ottens, A. J. (2005). The seven-stage crisis intervention model: A road map to goal attainment, problem solving, and crisis resolution. Brief Treatment and Crisis Intervention, 5(4), 329-339. https://doi.org/10.1093/brief-treatment/mhi030.
Schön, D. A. (1983). The reflective practitioner: How professionals think in action. New York: Basic Books.

Straussner, S., \& Calnan, A. (2014). Trauma through the life cycle: A review of current literature. Clinical Social Work Journal, 42(4), 323-335. https://doi.org/10.1007/s10615-014-0496-z.

Tosone, C. (2011). The legacy of September 11: Shared trauma, therapeutic intimacy, and professional posttraumatic growth. Traumatology, 17(3), 25-29. https://doi.org/10.1177/1534765611421963.

Tosone, C., Bialkin, L., Campbell, M., Charters, M., Gieri, K., Gross, S., et al. (2003). Shared trauma: Group reflections on the september 11th disaster. Psychoanalytic Social Work, 10(1), 57-77. https ://doi.org/10.1300/J032v10n01_06.

Tosone, C., Nuttman-Shwartz, O., \& Stephens, T. (2012). Shared trauma: When the professional is personal. Clinical Social Work Journal, 40(2), 231-239. https://doi.org/10.1007/s1061 5-012-0395-0.

Walsh, F. (2003). Crisis, trauma, and challenge: A relational resilience approach for healing, transformation, and growth. Smith College Studies in Social Work, 74(1), 49-71. https://doi. org/10.1080/00377310309517704.

Wayne, J., Raskin, M., \& Bogo, M. (2010). Field education as the signature pedagogy of social work education. Journal of Social Work Education, 46(3), 327-339. https://doi.org/10.5175/ JSWE.2010.200900043.

Wertheimer, M., \& Sodhi, M. (2014). Beyond field education: Leadership of field directors. Journal of Social Work Education, 50(1), 48-68. https://doi.org/10.1080/10437797.2014.856230.

Wilkerson, D. A., Wolfe-Taylor, S. N., Deck, C. K., Wahler, E. A., \& Davis, T. S. (2020). Telebehavioral practice basics for social worker educators and clinicians responding to COVID-19. Social Work Education, 39(8), 1137-1145. https://doi.org/10.1080/02615 479.2020.1807926.

Wolf, L., \& Goldkind, L. (2016). Digital native meet friendly visitor: A Flexner-inspired call to digital action. Journal of Social Work Education, 52, 99-109. https://doi.org/10.1080/10437 797.2016.1174643.

Publisher's Note Springer Nature remains neutral with regard to jurisdictional claims in published maps and institutional affiliations.

Anne Dempsey is a Clinical Assistant Professor at the NYU Silver School of Social Work and a Lead Instructor in the Field Learning curriculum area. Professor Dempsey's interests include teaching and learning in social work education, the use of simulation and technology in the classroom, psychotherapy, chronic illness, and trauma. 